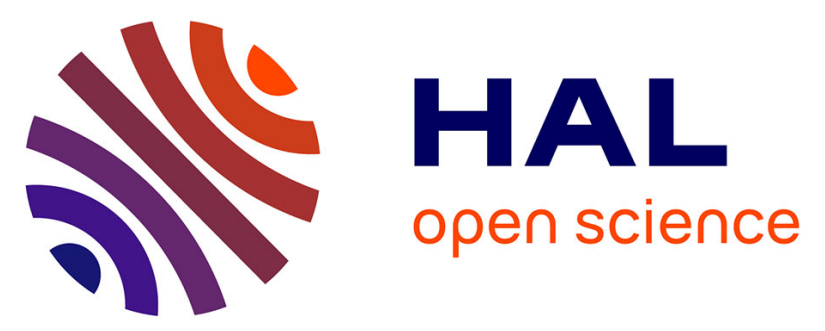

\title{
Simplification of first-line antibacterial regimen for complicated appendicitis in children was associated with better adherence to guidelines, and reduced use of antibiotics
}

Marion Taleb, Nicolas Nardi, Alexis Arnaud, Nathalie Costet, Pierre-Yves

Donnio, Charlotte Engrand, Edouard Habonimana, Eric Wodey, Pierre

Tattevin

\section{- To cite this version:}

Marion Taleb, Nicolas Nardi, Alexis Arnaud, Nathalie Costet, Pierre-Yves Donnio, et al.. Simplification of first-line antibacterial regimen for complicated appendicitis in children was associated with better adherence to guidelines, and reduced use of antibiotics. International Journal of Antimicrobial Agents, 2018, 52 (2), pp.293-296. 10.1016/j.ijantimicag.2018.04.010 . hal-01807363

HAL Id: hal-01807363

https://hal-univ-rennes1.archives-ouvertes.fr/hal-01807363

Submitted on 20 Jun 2018

HAL is a multi-disciplinary open access archive for the deposit and dissemination of scientific research documents, whether they are published or not. The documents may come from teaching and research institutions in France or abroad, or from public or private research centers.
L'archive ouverte pluridisciplinaire HAL, est destinée au dépôt et à la diffusion de documents scientifiques de niveau recherche, publiés ou non, émanant des établissements d'enseignement et de recherche français ou étrangers, des laboratoires publics ou privés. 


\section{HighLights}

- A switch from aminoglycoside-containing 3-drug regimen to piperacillin-tazobactam as the first-line treatment for complicated appendicitis in children allowed a dramatic reduction of protocols deviation, and antibacterial treatment duration

- No impact was observed on outcomes (post-operative complications, duration of hospital stay)

- Female gender and sepsis or septic shock on admission were the only variables independently associated with post-operative intra-abdominal abscess 


\section{Simplification of first-line antibacterial regimen for complicated}

\section{appendicitis in children was associated with better adherence to}

\section{guidelines, and reduced use of antibiotics}

Marion Taleb, ${ }^{\mathrm{a}}$ Nicolas Nardi, ${ }^{\mathrm{a}}$ Alexis Arnaud, ${ }^{\mathrm{b}}$ Nathalie Costet, ${ }^{\mathrm{c}}$ Pierre-Yves

Donnio, ${ }^{\mathrm{d}}$ Charlotte Engrand, ${ }^{\mathrm{a}}$ Edouard Habonimana, ${ }^{\mathrm{b}}$ Eric Wodey, ${ }^{\mathrm{a}}$ and Pierre Tattevin*e $^{\mathrm{e}}$

${ }^{a}$ Department of Anesthesiology, Rennes University Hospital, France

${ }^{b}$ Department of Pediatric Surgery, Rennes University Hospital, France

${ }^{c}$ Department of Biostatistics UMR Inserm 1099 LTSI Rennes 1 University, France

${ }^{d}$ Department of Infection Control and Prevention, Rennes University Hospital, France

${ }^{e}$ Infectious Diseases and Intensive Care Unit, Rennes University Hospital, France

* Corresponding author.Infectious Diseases and Intensive Care Unit, Pontchaillou University Hospital, 2, rue Le Guilloux, 35033 Rennes Cedex, France. Tel +33 299289564. Fax +33

299282452 E-mail address: pierre.tattevin@chu-rennes.fr

Declarations of interest: none 


\section{ABSTRACT}

Acute appendicitis in children requires early surgery, and a short course of antibiotics active on Enterobacteriaceae and anaerobes. Although aminoglycoside-containing 3-drug regimen have been used successfully for decades, simpler regimens with similar efficacy are increasingly used. We aimed to evaluate the impact of a switch from the combination of cefotaxime, metronidazole, and gentamicin (regimen 1), to piperacillin-tazobactam (regimen 2), as first-line regimen for complicated acute appendicitis in children. We enrolled 171 children, with a median age of 10 years [interquartile range, 6-13], treated with regimen 1 ( $\mathrm{n}=80$, April 2011-March 2013), or regimen 2 ( $\mathrm{n}=91$, April 2013-March 2015), after surgery for complicated acute appendicitis. The two groups were comparable, except for surgical approach (through laparoscopy in $46 \%$ of children before antibacterial regimen switch, versus $88 \%$ thereafter, $P<0.001)$. Post-operative complications and durations of hospital stay were similar. Deviations from antibacterial treatment protocol decreased from $37 \%(29 / 80)$ to $14 \%$ (13/91, $P<0.001)$, with a dramatic reduction of antibacterial treatment duration, from a median of 15 days [12-16], to 5 days [5-8], $P<0.001$. Post-operative intra-abdominal abscess developed in 32 children (18.7\%). Female gender (OR 2.76; 95\% confidence interval [1.186.48], $P=0.02)$ and sepsis or septic shock on admission ( $\mathrm{OR}=4.72[1.12-19.97], P=0.035)$ were independently associated with post-operative intra-abdominal abscess, but not antibacterial regimen. This study shows that simplication of first-line antibacterial regimen for complicated appendicitis in children was associated with reduced protocol deviation, reduced duration of antiobiotics, and similar outcomes in terms of post-operative complications, and duration of hospital stay.

Keywords : piperacillin-tazobactam; aminoglycoside; appendicitis; protocol; adherence; antimicrobial stewardship 


\section{Introduction}

Acute appendicitis is a common surgical condition that affects $0.3-0.4 \%$ of children, with a peak incidence between 8 and 13 years. Most common complications include perforation, peritonitis, and abscess, found in $25-39 \%$ of cases [1]. Treatment of acute appendicitis usually relies on early surgery (appendectomy, and management of complications when necessary), and a short course of antibiotics (4-7 days) [2], although highly selected patients with a well circumscribed focus of infection may be cured by antimicrobial therapy alone [3]. Aminoglycoside-containing 3-drug regimen have been used successfully for decades to treat complicated intra-abdominal infections in children, although simpler regimens, such as broadspectrum betalactam-betalactamase inhibitor combination, are of similar efficacy [3-6].

In March 2013, a local multidisciplinary group of professionals involved in the care of children with appendicitis, including pediatric surgeon, anesthesiologist, microbiologist, and infectious diseases physician, modified the first-line antibacterial treatment of appendicitis for children in our institution, with two objectives: i) to decrease the complexity of workload for nurses, and rates of deviation from the previous protocol, i.e. the triple combination of cefotaxime, gentamicin, and metronidazole; ii) to reduce the rate of post-operative intraabdominal abscess, from a baseline range of $15-20 \%$ in 2008-2012. In April 2013, piperacillin-tazobactam became the first-line regimen for all children operated for complicated appendicitis, and was incorporated in the computerized system for drug prescription, with standard duration, intervals, and weight-based dose. In addition, a specific note against the use of oral switch beyond day five for children with favorable outcome was added in the protocol. The main objective of this study was to evaluate the impact of these protocol changes on the incidence of post-operative complications. Secondary objectives were the evaluation of protocol deviations, and the analysis of risk factors for post-operative intraabdominal abscess. 


\section{Materials and methods}

\subsection{Study design}

We performed a retrospective, observational study of all children < 18-year old who underwent surgery for complicated appendicitis from April 2011 to March 2015 in the Rennes university hospital, Western France. Cases were identified through the computerized database of the pediatric surgery department. Complicated appendicitis were defined as appendicitis that required surgery, associated with at least one of the followings, reported in the surgery report: i) abscess; ii) local peritonitis; iii) disseminated peritonitis. Data were collected from medical files by one investigator (MT), on a standardized questionnaire, including demographic information (age, weight, sex), comorbidities, septic shock or sepsis (according to 2016 definition [7]), surgical approach, timing, doses, and duration of antibacterial treatment, post-operative complications, and length of hospital stay. The study was approved by our institutional review board.

\subsection{Procedures}

From April 2011 to March 2013 (former protocol group, G1), most children received intravenous cefotaxime (150 mg/kg/day), and intravenous metronidazole (35 mg/kg/day) for at least 5 days, associated with intravenous gentamicin $(5 \mathrm{mg} / \mathrm{kg} / \mathrm{day})$, for the first 3 days. From April 2013 to March 2015 (new protocol group, G2), most children received intravenous piperacillin-tazobactam, $250 \mathrm{mg} / \mathrm{kg} /$ day, for at least 5 days. Children with sepsis also received intravenous gentamicin $(5 \mathrm{mg} / \mathrm{kg}$ /day), for the first 3 days. A switch to oral antibiotics (mostly amoxicillin-clavulanate) was left to the discretion of the surgeon before April 2013 (G1), while it was specifically not recommended thereafter (G2). Surgical treatment was performed by a senior surgeon, and included appendectomy, performed by 
laparoscopy or open surgery, at the discretion of the surgeon, associated with source control, whenever required. All children were re-evaluated one month after appendectomy.

\subsection{Statistics}

Continuous variables were expressed as median [quartile 1-quartile 3], and compared using Student t-test or Mann-Whitney U-test. Categorical variables were expressed as numbers (\%), and compared using $\mathrm{Chi}^{2}$ or Fisher exact tests. $\mathrm{P}<0.05$ was considered statistically significant. For multivariate analysis of risk factors for intra-abdominal abscess, all variables with $\mathrm{P}<0.2$ by univariate analysis were evaluated using a stepwise logistic regression model. Logistic regression analyses were performed using SPSS software, version 16.0 .

\section{Results}

During the study period, 171 children operated for acute appendicitis fulfilled inclusion criteria: 80 from April 2011 to March 2013 (G1), and 91 from April 2013 to March 2015 (G2). Baseline characteristics and management were similar in both groups (Table 1), except for surgical technique, as appendectomy was performed through laparoscopy in $80 \%$ of children in G2, as compared to only $37 \%$ in G1 $(P<0.0001)$. Incidence and characteristics of post-operative complications were also similar in both groups, as were durations of intravenous antibacterial treatment, and hospital stay. Of note, deviations from antibacterial treatment procedures were observed in $37 \%$ (29/80) of children in G1, as compared to $14 \%$ $(13 / 91)$ in $\mathrm{G} 2(P<0.001)$. This improvement was mostly related to deviations regarding antibacterial treatment duration, that decreased from $33 \%(26 / 80)$, to $8 \%(7 / 91)$. Consequently, the median duration of antibacterial treatment was dramatically reduced from a median of 15 days [12-16] in G1, to 5 days [5-8] in G2, $P<0.001$. 
Post-operative intra-abdominal abscess developed in 32 children (18.7\%). Bivariate and multivariate analysis of risk factors are presented in Table 2. Female gender (OR 2.76; $95 \%$ confidence interval [1.18-6.48], $P=0.02)$ and sepsis or septic shock on admission $(\mathrm{OR}=$ 4.72 [1.12-19.97], $P=0.035)$ were the two variables independently associated with an increased risk of post-operative intra-abdominal abscess.

\section{Discussion}

The major findings of this study are as follows: i) the simplification of first-line antibacterial treatment for children with complicated appendicitis, from an aminoglycosidecontaining 3-drug regimen (cefotaxime-metronidazole-gentamicin), to a broad-spectrum betalactam-betalactamase inhibitor combination (piperacillin-tazobactam), was not associated with any significant change in terms of post-operative complications; ii) a specific recommendation against the use of oral switch after discharge for children with favorable outcome at day five post-surgery was associated with a dramatic decrease in the median duration of antibacterial treatment, from 15 days to 5 days $(P<0.001)$, again with no measurable increase in the incidence of adverse events; iii) both changes were associated with a lower rate of deviations from our local protocol; iv) however, despite these achievements, we failed to reduce the rate of post-operative intra-abdominal abscess. Of note, female sex, and sepsis or septic shock, were the only independent predictor of intra-abdominal abscess in our study.

Major pathogens in complicated appendicitis are coliforms (Enterobacteriaceae, especially Escherichia coli), anaerobes (primarily Bacteroides fragilis), and Streptococcus sp., mostly milleri group streptococci $[3,8]$. Pseudomonas aeruginosa has been identified in $5-19 \%$ of community-acquired appendicitis in children, but its pathogenicity has not been proven in this context, so that antibacterial regimens with no anti-pseudomonal activity (e.g. 
third-generation cephalosporin plus metronidazole) are among the most common first-line regimens for complicated appendicitis worldwide $[1,2,4,9,10]$. Intra-operative culture swabs are not routinely recommended for appendicitis, due to the complexity of microbiological patterns, and the limited impact on patients care, as final results with drug susceptibility testing become available by the time antibacterial treatment is no longer necessary [11]. However, due to marked differences in susceptibility patterns between different communities and institutions, sentinel studies repeated over time with routine cultures and drug susceptibility testing are required to monitor the appropriateness of first-line regimens. If resistance to a regimen is present in $>10 \%$ of isolates of a common intraabdominal pathogen in the community, use of that regimen should be avoided [3]. Three recent French studies have examined the bacterial ecology of acute appendicitis in children [8, $12,13]$ : The majority of intraoperative specimens were polymicrobial $(60-77 \%)$, and included E. coli (51-71\%), streptococci (9-22\%), strict anaerobes (mostly B. fragilis, 20-33\%), and $P$. aeruginosa 6-19\%. Piperacillin-tazobactam, active on 97\% of isolates in a recent study from our area [12], was thus selected as the preferred first-line regimen in our local protocol. Although this broad-spectrum antibiotic certainly increases the risk of multidrug-resistance, and Clostridium difficile infection, there is no robust data to suggest that piperacillintazobactam has more impact on microbiota than the triple combination of cefotaxime, metronidazole, and gentamicin. In addition, as the implementation of the new protocol was associated with a dramatic reduction of total antibacterial treatment duration (i.e., from a median of 15 days [12-16], to a median of 5 days 15 [5-8]), the overall impact on microbiota may have been reduced with the new protocol, although we have no data to support this. Considerations of simplicity (low number of injections), and cost, are additional assets for this regimen $[14,15]$, in line with recent guidelines from the Surgical Infection Society [4], the American Pediatric Surgical Society [2], and the Infectious Diseases Society of America [3]. 
These latter guidelines advocated for the development of local clinical pathways to standardize the management of appendicitis, with compelling evidence that it improves both the process of care, and patient outcomes [3]. Although our efforts to refine appendicitis pathway were successful regarding process of care, with better standardization (i.e. lower rate of protocol deviation), and a dramatic decrease of unnecessary use of antibiotics, we found no measureable impact on patients outcomes, with a rate of post-operative intra-abdominal abscess that remained within the baseline $15-20 \%$ range. Other studies on this issue were similarly 'half-successful', with significant improvement in antimicrobial prescribing, and/or better adherence to clinical practice guidelines, but no measurable impact on outcome $[2,6$, $15,16]$.

This study has limitations: firstly, there are potential biases due to its observational, quasi-experimental design. Of note, surgical practices for appendicitis dramatically changed during the study period, with a gradual switch from open surgery to laparoscopy. However, rates of post-operative complications are similar with these two approaches [3]. In addition, neither surgery type, nor study period, were associated with intra-abdominal abscess in our bivariate and multivariate analysis. Secondly, findings of this single-center study may not be generalizable to other context, especially in areas with different microbiological and resistance patterns. Thirdly, sample size was limited. However, this study adds another brick in the wall by demonstrating that the development of local protocol by a multidisciplinary team, with simple first-line regimen adapted to microbiological epidemiology, may improve the care of children with complicated appendicitis, and reduce the unnecessary use of antibiotics. 


\section{Declarations}

Funding: None

Competing Interests: None

Ethical Approval: Ethical approval given

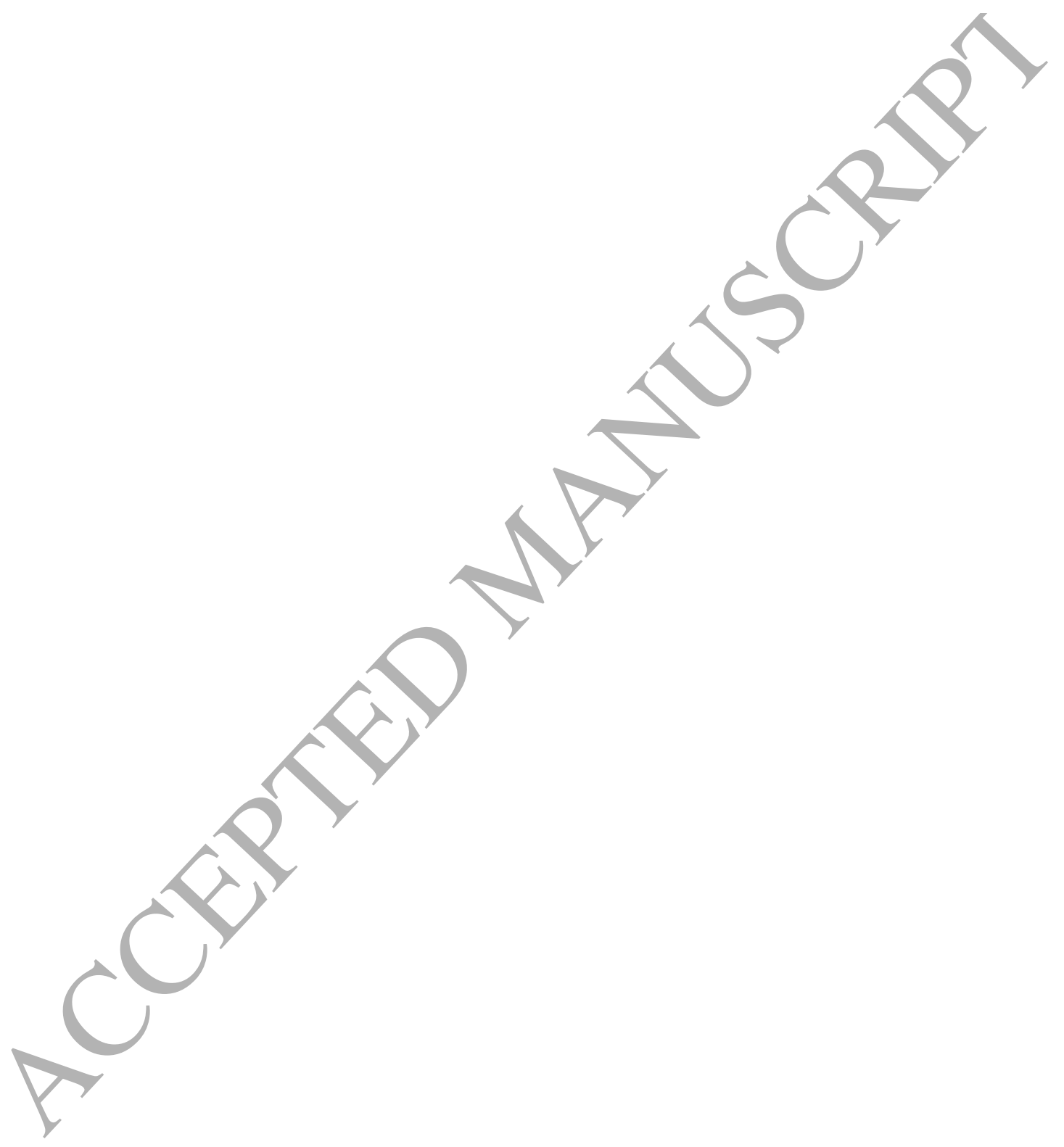




\section{References}

1. Meier, D.E., et al., Perforated appendicitis in children: is there a best treatment? J Pediatr Surg, 2003. 38(10): p. 1520-4.

2. Lee, S.L., et al., Antibiotics and appendicitis in the pediatric population: an American Pediatric Surgical Association Outcomes and Clinical Trials Committee systematic review. J Pediatr Surg, 2010. 45(11): p. 2181-5.

3. Solomkin, J.S., et al., Diagnosis and management of complicated intra-abdominal infection in adults and children: guidelines by the Surgical Infection Society and the Infectious Diseases Society of America. Clin Infect Dis, 2010. 50(2): p. 133-64.

4. Nadler, E.P. and B.A. Gaines, The Surgical Infection Society guidelines on antimicrobial therapy for children with appendicitis. Surg Infect (Larchmt), 2008. 9(1): p. 75-83.

5. Nadler, E.P., et al., Monotherapy versus multi-drug therapy for the treatment of perforated appendicitis in children. Surg Infect (Larchmt), 2003. 4(4): p. 327-33.

6. Goldin, A.B., et al., Aminoglycoside-based triple-antibiotic therapy yersus monotherapy for children with ruptured appendicitis. Pediatrics, 2007. 119(5): p. 905-11.

7. Singer, M., et al., The Third International Consensus Definitions for Sepsis and Septic Shock (Sepsis-3). Jama, 2016. 315(8): p. 801-10.

8. Schmitt, F., et al., Bacterial studies of complicated appendicitis over a 20-year period and their impact on empirical antibiotic treatment. J Pediatr Surg, 2012. 47(11): p. 2055-62.

9. Kronman, M.P., et al., Extended-Versus Narrower-Spectrum Antibiotics for Appendicitis. Pediatrics, 2016. 138(1).

10. Lelli, J.L., Jr., et al., Historical changes in the postoperative treatment of appendicitis in children: impact on medical outcome. J Pediatr Surg, 2000. 35(2): p. 239-44; discussion 244-5.

11. Foo, F.J., I.J. Beckingham, and I. Ahmed, Intra-operative culture swabs in acute appendicitis: a waste of resources. Surgeon, 2008. 6(5): p. 278-81.

12. Guillet-Caruba, C., et al., Bacteriologic epidemiology and empirical treatment of pediatric complicated appendicitis. Diagn Microbiol Infect Dis, 2011. 69(4): p. 376-81.

13. Dumont, R., et al., The Microbiology of Community-acquired Peritonitis in Children. Pediatr Infect Dis J, 2011. 30(2): p. 131-5.

14. St Peter, S.D., et al., Single daily dosing ceftriaxone and metronidazole vs standard triple antibiotic regimen for perforated appendicitis in children: a prospective randomized trial. J Pediatr Surg, 2008. 43(6): p. 981-5.

15. Fishman, S.J., et al., Perforated appendicitis: prospective outcome analysis for 150 children. J Pediatr Surg, 2000. 35(6): p. 923-6.

16. Willis, Z.I. et al., Improvements in Antimicrobial Prescribing and Outcomes in Pediatric Complicated Appendicitis. Pediatr Infect Dis J, 2017. 
Table 1. Comparison of children operated for complicated appendicitis from April 2011 to March 2013 (group1, first-line antibacterial treatment cefotaxime-metronidazole-gentamicin), and from April 2013 to March 2015 (group 2, first-line antibacterial treatment piperacillintazobactam)

\begin{tabular}{|c|c|c|c|}
\hline & $\begin{array}{c}\text { Group } 1 \\
\mathbf{n = 8 0}\end{array}$ & $\begin{array}{c}\text { Group } 2 \\
\mathbf{n}=91\end{array}$ & $\boldsymbol{P}$ \\
\hline Age, years & $9[5-13]$ & $10[7-13]$ & 0.503 \\
\hline Female sex & $35(44)$ & & 0.579 \\
\hline Weight, $\mathrm{kg}$ & $32[22-48]$ & $34[25-45]$ & 0.834 \\
\hline \multicolumn{4}{|l|}{ Baseline complications } \\
\hline - Abscess & $14(17)$ & $17(19)$ & 0.841 \\
\hline - Localized peritonitis & & $34(37)$ & 0.623 \\
\hline - Disseminated peritonitis & & $40(44)$ & 0.530 \\
\hline Sepsis*/septic shock & & $7(8)$ & 0.712 \\
\hline \multicolumn{4}{|l|}{ Surgery type } \\
\hline - laparoscopy & $(46)$ & $80(88)$ & $<0.001$ \\
\hline - open appendicectomy & $43(54)$ & $11(12)$ & $<0.001$ \\
\hline Time between admission and surgery, hours & $8[6-17]$ & $8[6-18]$ & 0.674 \\
\hline $\begin{array}{l}\text { Time between first administ } \\
\text { antibiotic and surgery, hours }\end{array}$ & $0[0-9]$ & $1[0-6]$ & 0.934 \\
\hline \multicolumn{4}{|l|}{ Outcome } \\
\hline Infectious complications & $15(19)$ & $23(25)$ & 0.304 \\
\hline - $\quad$ surgical site infections & $7(9)$ & $5(5)$ & 0.406 \\
\hline - intra-abdominal abscess & $12(15)$ & $20(22)$ & 0.240 \\
\hline Intravenous antibiotic duration, days & $5[5-7]$ & $5[5-7]$ & 0.752 \\
\hline Intravenous + oral antibiotic duration, days & $15[12-16]$ & $5[5-8]$ & $<0.001$ \\
\hline Hospital stay, days & $6[5-8]$ & $6[5-7]$ & 0.856 \\
\hline Protocol deviations & $29(37)$ & $13(14)$ & $<0.001$ \\
\hline - deviation in terms of antibiotic regimen & $5(6)$ & $6(7)$ & 0.912 \\
\hline - deviation in terms of antibiotic duration & $26(33)$ & $7(8)$ & $<0.001$ \\
\hline
\end{tabular}

Qualitative data are expressed as numbers (percentages). Quantitative data are expressed as medians [quartile 1-quartile 3]. *We used the 2016 definition for sepsis, i.e. life-threatening organ dysfunction caused by a dysregulated host response to infection. 
Table 2. Univariate and multivariate analysis of risk factors for intra-abdominal abscess

\begin{tabular}{|c|c|c|c|c|}
\hline & $\begin{array}{c}\text { Intra- } \\
\text { abdominal } \\
\text { abscess } \\
\mathbf{n}=\mathbf{3 2}\end{array}$ & $\begin{array}{c}\text { No intra- } \\
\text { abdominal } \\
\text { abscess } \\
\text { n=139 }\end{array}$ & $\begin{array}{c}\text { Bivariate } \\
\text { analysis } \\
P\end{array}$ & $\begin{array}{l}\text { Multivariate } \\
\text { analysis ** } \\
\text { OR }[95 \% \mathrm{CI}]\end{array}$ \\
\hline Age, years & $11[7-14]$ & $9[6-13]$ & 0.139 & \\
\hline Female sex & $14(44)$ & $56(40)$ & 0.115 & $6.48]$ \\
\hline Weight, $\mathrm{kg}$ & $41[26-56]$ & $32[23-45]$ & 0.122 & \\
\hline \multicolumn{5}{|l|}{ Baseline complications } \\
\hline - Abscess & $7(22)$ & $24(17)$ & & \\
\hline - Localized peritonitis & $5(16)$ & b) & 0.623 & \\
\hline - Disseminated peritonitis & $20(62)$ & & 0.530 & \\
\hline Sepsis*/septic shock & $7(22)$ & & 0.002 & 4.72 [1.12-11.97] \\
\hline $\begin{array}{l}\text { Surgery type } \\
-\quad \text { laparoscopy } \\
-\quad \text { open appendicectomy }\end{array}$ & & $\begin{array}{l}93(67) \\
46(33)\end{array}$ & 0.335 & \\
\hline $\begin{array}{l}\text { Time between admission and } \\
\text { surgery, hours }\end{array}$ & & $8[6-18]$ & 0.715 & \\
\hline $\begin{array}{l}\text { Time between first } \\
\text { administration of antibiotic }\end{array}$ & $0[0-11]$ & $1[0-6]$ & 0.609 & \\
\hline
\end{tabular}

Qualitative data are expressed as numbers (percentages). Quantitative data are expressed as medians [quartile 1-quartile 3].

OR, odds ratio; $\mathrm{CI}$, confidence interval

*We used the 2016 definition for sepsis, i.e. life-threatening organ dysfunction caused by a dysregulated host response to infection.

** For multivariate analysis of risk factors for intra-abdominal abscess, all variables with

$\mathrm{P}<0.2$ by univariate analysis were evaluated using a stepwise logistic regression model. 